\title{
Ramsay-Hunt syndrome and subsequent sensory neuropathy as potential immune- related adverse events of nivolumab: a case report
}

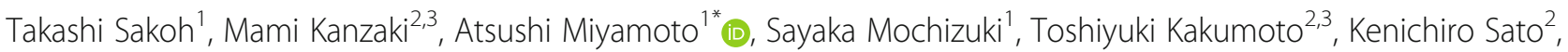
Yoshikazu Uesaka ${ }^{2,3}$ and Kazuma Kishi ${ }^{1,3}$

\begin{abstract}
Background: Nivolumab is an immune checkpoint inhibitor $(\mathrm{ICl})$ and is used for the treatment of advanced nonsmall cell lung cancer (NSCLC). Several immune-mediated neurological adverse events associated with ICls have been reported to date, such as Guillain-Barré syndrome. Nivolumab-associated neurological adverse events can vary, and their etiology remains unclear.

Case presentation: A 72-year-old man with NSCLC was treated with nivolumab as a second-line therapy. After 13 rounds of nivolumab therapy, he presented with Ramsay-Hunt syndrome (RHS) followed by acute ataxic sensory neuropathy. Antiviral therapy for Varicella-Zoster virus and prednisolone resulted in partial improvement of RHS, while almost no recovery was observed in the sensory neuropathy. However, the sensory ataxia significantly improved after intravenous immunoglobulin (IVIg) therapy, and interestingly, the facial palsy associated with RHS also improved. The neurological manifestations, nerve conduction study result, and imaging findings supported that dorsal root ganglia were the primary lesion site of acute ataxic sensory neuropathy.
\end{abstract}

Conclusions: Our case presented with the comorbidity of RHS and subsequent ataxic sensory neuropathy after nivolumab therapy to whom IVIg was effective. Our case suggested the wide variability of possible neurological symptoms, and the potential usefulness of IVIg to sensory ataxic neuropathy, seen in cancer patients with ICI treatment.

Keywords: Immune checkpoint inhibitor, Intravenous immunoglobulin, Lung cancer, Neurological adverse events, Nivolumab, Ramsay-Hunt syndrome, Sensory neuropathy

\section{Background}

Nivolumab is an immune checkpoint inhibitor (ICI) that targets programmed cell death-1 (PD-1) receptors, and is used for the treatment of advanced non-small cell lung cancer (NSCLC) in patients who did not respond to first-line chemotherapy $[1,2]$.

Several neurological adverse events associated with ICIs have been reported, such as neuropathy, encephalitis, chronic inflammatory demyelinating polyneuropathy, Guillain-Barré syndrome (GBS), myasthenia gravis,

\footnotetext{
* Correspondence: atsushimotty@gmail.com

${ }^{1}$ Department of Respiratory Medicine, Toranomon Hospital (Branch), 1-3-1

Kajigaya, Takatsu-ku, Kawasaki-shi, Kanagawa 213-8587, Japan

Full list of author information is available at the end of the article
}

etc. [3-7], the underlying mechanisms of which are not yet fully understood. It is suspected that the loss of $\mathrm{T}$ cell inhibition via PD-1 blockade leads to impaired selftolerance due to prior subclinical autoimmune disease or cross-reactivity of nervous system antigens with those of tumors [8], and this is considered to result in immune-mediated neurological adverse events [6]. In addition, since the use of ICIs can result in infections including opportunistic meningitis or Varicella-Zoster virus (VZV) reactivation [7, 9], ICI-associated neurological disorders can also be mediated by infectious etiologies. Thus, the spectrum of nivolumab-associated neurological adverse events could be wide. However, due to the lack of accumulation of the literature of clinical

(c) The Author(s). 2019 Open Access This article is distributed under the terms of the Creative Commons Attribution 4.0 International License (http://creativecommons.org/licenses/by/4.0/), which permits unrestricted use, distribution, and reproduction in any medium, provided you give appropriate credit to the original author(s) and the source, provide a link to the Creative Commons license, and indicate if changes were made. The Creative Commons Public Domain Dedication waiver (http://creativecommons.org/publicdomain/zero/1.0/) applies to the data made available in this article, unless otherwise stated. 
detailed and appropriate findings in the real world, the detailed etiologies of the neurological adverse events by ICIs are a sparsely investigated topic.

Here, we report the case of a 72-year-old man with NSCLC, who presented with Ramsay-Hunt syndrome (RHS) and acute sensory neuropathy, both of which may be associated with the use of nivolumab.

\section{Case presentation}

A 71-year-old man with severe cough presented with left-sided pleural effusion. After thoracentesis, he was diagnosed with lung adenocarcinoma with malignant effusion without activating epidermal growth factor receptor mutations and anaplastic lymphoma kinase rearrangements (clinical T1aN3M1a, stage IVa). He was a former smoker with a smoking index of 15 pack-years. He was an electrical engineer with a history of occupational Xray exposure. Four cycles of carboplatin (area under the blood concentration-time curve of $6 \mathrm{mg} / \mathrm{mL} \mathrm{min}$ ) and pemetrexed (PEM, $500 \mathrm{mg} / \mathrm{m}^{2}$ ) were administered, followed by talc pleurodesis. Thereafter, six cycles of maintenance therapy with PEM were performed. Disease progression after 9 months from his first chemotherapy session led him to receive nivolumab as a second line therapy (Fig. 1a-c). He received nivolumab $(3 \mathrm{mg} / \mathrm{kg}$ ) every 2 weeks for a total of 13 rounds. Nivolumab resulted in a partial response only with grade 3 lymphocytopenia (approximately 300-400 cells/ $\mu \mathrm{L}$ ) (Fig. 1d and f).

Four days after the 13th nivolumab administration, he developed otitis externa on his left ear and it got worse. Moreover, an additional 4 days later, he developed unsteadiness on standing with acute onset. His initial neurological findings revealed sensory ataxia of his four extremities: positive Romberg's test, decreased vibration sense of the bilateral ankles, and poor proprioception of his bilateral upper limbs, with no significant limb weakness, pyramidal signs, or decrease in superficial sensation. Four days after the onset of unsteadiness, his temperature increased $\left(39.0^{\circ} \mathrm{C}\right)$ without headache or meningism. Brain magnetic resonance imaging (MRI) was not suggestive of carcinomatous meningitis or metastatic lesions. Contrast-enhanced MRI was performed to monitor the spinal cord and brachial plexus, and yielded no abnormal findings.

His otitis externa was diagnosed as VZV infection of the left external auditory canal due to VZV reactivation.

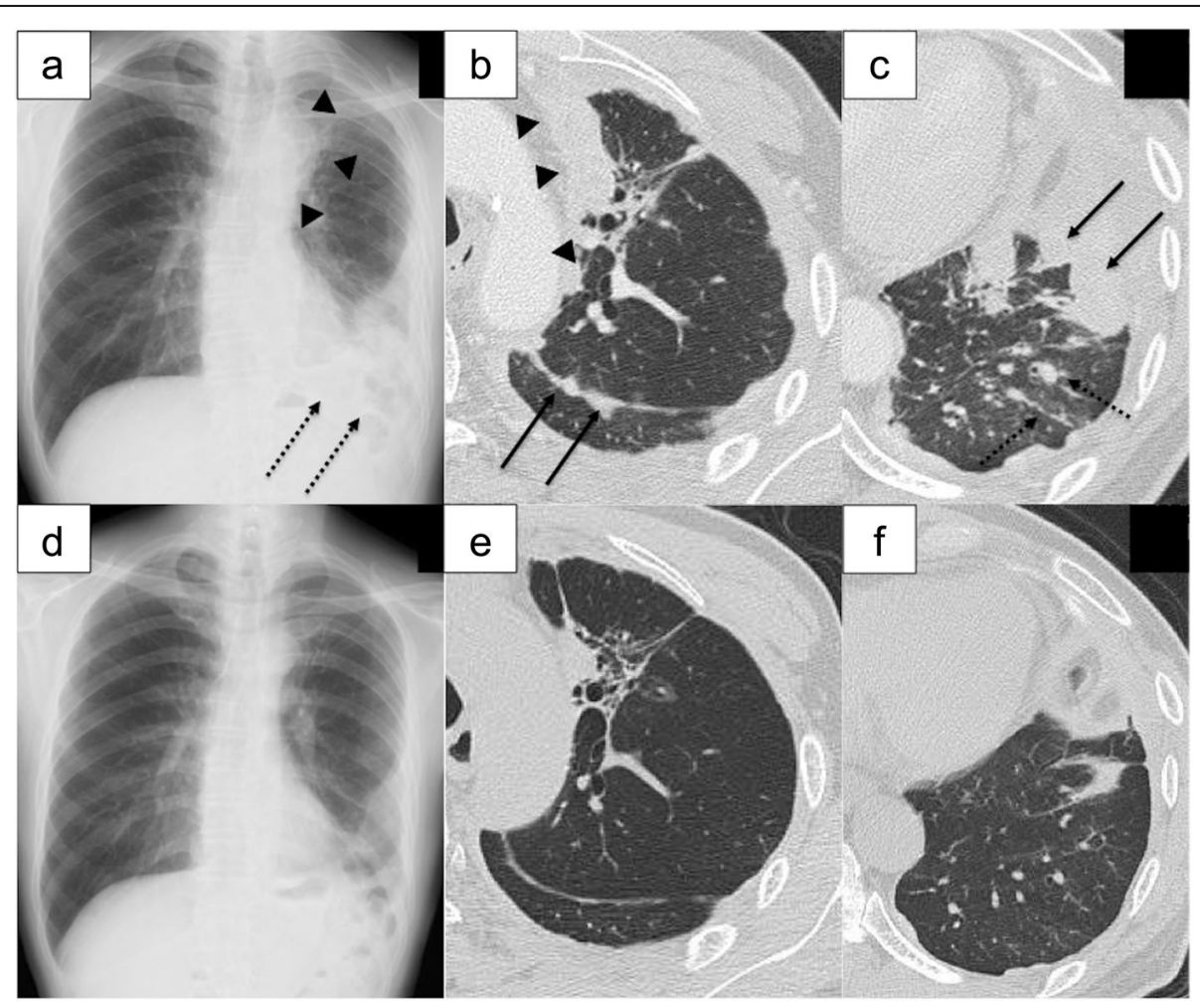

Fig. 1 Chest imaging findings, Chest imaging at baseline (a-c), and after 13 rounds of nivolumab treatment (d-f), On the chest x-ray, primary tumor was shown in the upper lung field in contact with upper mediastinum (arrow heads), and disseminated tumor masses were mainly identified in the left lower lung field as a consolidated area (black dotted heads) (a) and were improved after nivolumab therapy (d). On the chest computed tomography image, the primary lesion in the left upper lobe adjacent to mediastinum (black arrow heads), disseminated multiple masses in the thoracic cavity (black solid arrows), and pleural and interlobular septal thickening due to lymphatic spread of tumors (black dotted arrows) (b, c) were all improved after nivolumab therapy $(\mathbf{e}, \mathbf{f})$ 
He clearly declared his childhood experience of chicken pox and no recent close contact with patients who suffered from VZV infection, and his serum immunoglobulin (Ig) status against VZV at his initial admission soon after developing his symptoms showed a significantly elevated level of serum IgG (44.2 antibody index by the enzyme immunoassay [EIA]: normal range of $<2.0)$ and a normal level of serum IgM ( 0.16 antibody index by the EIA: normal range of $<0.80$ ). He was admitted to our hospital 9 days after his initial symptom presentation and started aciclovir $(15 \mathrm{mg} / \mathrm{kg} /$ day: $900 \mathrm{mg} /$ day $)$ intravenously (day 1) for 7 days (Fig. 2). Cerebrospinal fluid (CSF) assessment on day 1 revealed an elevated white blood cell count $\left(63\right.$ cells $\left./ \mathrm{mm}^{3}\right)$, protein level $(62 \mathrm{mg} / \mathrm{dl})$, and IgG index score (0.76): this is simply calculated by the following equation:

$$
\operatorname{IgG} \text { index }=\left(\frac{C N S \operatorname{Ig} G}{C N S A l b}\right) \cdot\left(\frac{\text { serum } A l b}{\text { serum } I g G}\right)
$$

to see whether there may be intrathecal increase of IgG, and its normal range is 0.34-0.58 [10]. Meanwhile, no malignant cells were found and the glucose level was normal $(63 \mathrm{mg} / \mathrm{dl})$. In addition, the level of VZV-DNA was significantly increased $(10,000$ copies $/ \mathrm{ml}$, normal range $<200$ copies $/ \mathrm{ml}$ ). Following the development of otitis externa, left-sided facial nerve palsy was observed from day 2 and worsened to the most severe level (House-Brackmann grade 5) [11] on day 3 . These clinical features and laboratory data corresponded to RHS. We additionally administered $60 \mathrm{mg}$ of prednisolone on day 3 .

Nerve conduction studies (NCS) were performed on day 14 to evaluate his sensory ataxia. These studies revealed a significant reduction in the sensory nerve conduction velocity (SCV) with fewer sensory nerve action potentials (SNAPs) on the left median (SCV $37.2 \mathrm{~m} / \mathrm{s}$, SNAP $9.5 \mu \mathrm{V}$ ) and ulnar nerves (SCV $33.9 \mathrm{~m} / \mathrm{s}$, SNAP $7.5 \mu \mathrm{V})$, and no significant abnormal findings in compound motor action potentials. Sensory-dominant ataxic neuropathy was considered to be the most likely etiology. While the sensory ataxia was not improved by acyclovir and prednisolone treatments, a partial response was observed in the facial nerve palsy due to RHS, maintaining a House-Brackmann grade of 5 . We also performed somatosensory evoked potential (SEP) studies to assess neurological function, which revealed neuropathy instead of myelopathy. We opted to reduce the prednisolone dose and discharge the patient under close observation on day 16.

Since his unsteadiness worsened even after completion of aciclovir and reduction of prednisolone, he was readmitted to our hospital on day 20 (Fig. 2). We reevaluated the CSF on day 22 and found slight improvements in the white blood cell count $\left(14\right.$ cells $\left./ \mathrm{mm}^{3}\right)$ and protein level $(44 \mathrm{mg} / \mathrm{dl})$, and VZV-DNA was not detected. Spinal MRI again revealed no significant changes to support VZV encephalopathy or myelitis. Notably, 12 antibodies of paraneoplastic neurological syndromes

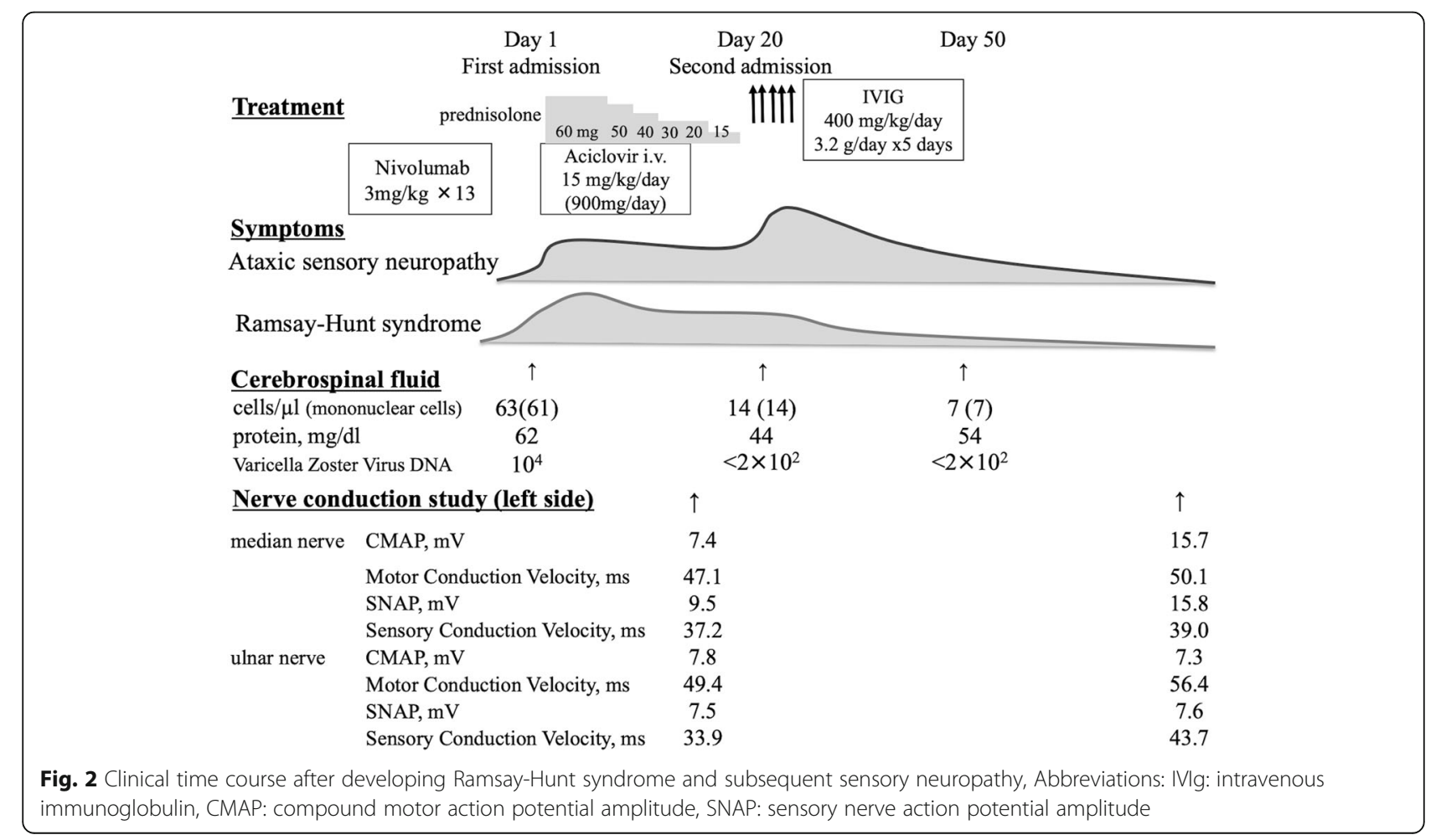


(PNS) (Hu, Yo, Ri, PNMA2, CV2, Amphiphysin, anti-Tr/ DNER, GAD65, ZIc4, Titin, SOX1, and Recoverin; examined using an immunoblotting method by BML Inc.) and anti-ganglioside antibodies including antiganglioside complexes in the serum were all negative on day 22. Since the sensory ataxia persisted even after treatment with aciclovir and a short course of prednisolone, we suspected an immune-mediated etiology other than VZV infection. Thus, we performed one course of intravenous immunoglobulin (IVIg) therapy $(400 \mathrm{mg} / \mathrm{kg} /$ day for 5 days [days 23-27]). Within 2 days, his facial nerve palsy had significantly improved (House-Brackmann grade 2), and his deep sensation also began to recover, which enabled him to take Romberg's and Mann's postures. Eventually, he was able to stand on his left leg at 15 days after the administration of IVIg (day 38). We confirmed abnormal NCS features with the delayed SCV and decreased SNAP amplitudes recovered on the median nerve (day 91).

During the treatment for RHS and ataxic sensory neuropathy, the status of lung cancer remained stable without the use of any chemotherapeutic agents.

\section{Discussion and conclusion}

While nivolumab provides us with a novel strategy to treat several cancers, acute-onset neurological adverse events including peripheral neuropathy, GBS, meningitis, neuromuscular disorders, and encephalitis have also been reported to present in $0.93 \%$ of 3763 advanced melanoma patients receiving nivolumab with or without ipilimumab [5]. The present case developed both RHS and sensory-dominant ataxic neuropathy after receiving nivolumab as a second-line therapy. The combination of RHS and ataxic sensory neuropathy and the significant improvements in the related symptoms by IVIg as observed in our case have not been documented previously.

RHS, which typically manifests as a triad of ipsilateral facial paralysis as a neurological deficit, ear pain, and vesicles in the auditory canal or on the auricle $[12,13]$, is often induced by reactivation of prior VZV infection in the geniculate ganglion [14], and has not been documented previously as an adverse event of ICIs. With regard to the pharmacological effect of nivolumab on the immune system, infectious adverse events should be inhibited in patients treated with ICI, as nivolumab induces an antitumor response by activating $\mathrm{T}$ cells [6]. This seems to be contradictory since the VZV reactivation requires disrupted T-cell mediated VZV immunity [15]. However, in the real world setting, previous reports have indicated that serious infection developed in $7.3 \%$ of 740 melanoma patients who received ipilimumab, nivolumab, or pembrolizumab. Although being rare, disseminated or facial VZV infection was indeed observed in patients who received ICIs [9] with unknown etiology.
Mild lymphocytopenia seen in our case might assist VZV reactivation [16]. Hence, there is no wonder to suspect the RHS due to VZV reactivation as one of the possible adverse events of nivolumab.

A previous study reported a case of sensory neuropathy as an adverse reaction of ICIs [7], but the detailed clinical presentation remains unknown. None of the previous studies reported the mechanism of sensorydominant ataxic neuropathy induced by ICIs. Physical, electrophysiological, and imaging findings comprehensively revealed that the cervical dorsal funiculus or dorsal root ganglia (DRG) were the exact disordered and causative legions of neuropathy, because no cervical lesions were found in MRI studies and because the SEP and NCS studies indicated the evidence of neuropathy, but not myelopathy. One possible explanation for nivolumab-induced sensory ataxia is the enhanced cytotoxicity of CD8-positive lymphocytes against selfantigens within DRG, which may occur due to crossreactivation by nivolumab and be enhanced by VZV reactivation. It was reported in some earlier studies that hantavirus-infected cells strongly express programmed cell death-ligand 1 (PD-L1) and PD-L2 to prevent damage by immune cells, and moreover, that lymphocytic choriomeningitis virus-infected cells were damaged by activated CD8-positive cells via blockade of PD-1 and PD-L1 binding [17]. These observational studies may indicate the importance of the PD-1 cascade in viral immunity, namely, that the loss of $\mathrm{T}$ cell inhibition via the cascade could attack DRG via self-antigens that crossreactivate with other antigens.

Our case showed significant responsiveness to IVIg treatment. IVIg treatment is reported to be effective for treating neuropathies due to nivolumab use $[6,7]$, and may also be effective in treating specific cases of VZVrelated neurological disorders [18, 19], although there are no sufficient data on the efficacy of IVIg for the treatment of VZV infection. Overt improvement in persistent facial paralysis with IVIg treatment may provide evidence that cytotoxic etiology, following VZV reactivation, is involved in its pathogenesis [18].

Taken together, the possible hypothesis for our case comorbid with sensory ataxia and VZV infection simultaneously is suspected as follows: Firstly, VZV in the patient's geniculate ganglion was reactivated by nivolumab; secondly, VZV was inhibited by aciclovir and prednisolone but the facial nerve dysfunction remained; thirdly, the DRG were damaged by CD8-positive cells activated by nivolumab due to cross-reactivity of antigens within the DRG, leading to subsequent sensory ataxic neuropathy; and finally, these immune-related neurological insufficiencies recovered after IVIg treatment. Although PNS is also known as a disease that mainly targets the DRG [20] and 
it remains a differential diagnosis for our patient, we believe that PNS is unlikely because the lung adenocarcinoma was well controlled and the tests for the 12 antibodies of PNS were negative.

Our report has several limitations. First, we cannot strictly determine that the sensory ataxic neuropathy in our case was due to the direct adverse event associated with nivolumab, or due to the subsequent comorbidity of VZV infection. Second, while we discussed the VZV involvement mainly as the reactivation in a close association with the nivolumab use and suggested the explicable hypothesis, its association was not strictly proven in our case. Third, because of his single time of the IgG and IgM status at-index admission, the reactivation of VZV due to other concomitant events, or the possibility of VZV primoinfection, were not strictly ruled out in our patient, based on his concurrent coexistence of lung cancer and the past history of chemotherapies prior to nivolumab.

In conclusion, our case presented with RHS and sensory dominant ataxic neuropathy following nivolumab administration, suggesting the wide variability of neurological symptoms potentially observed under ICI usage. Our case confirmed the significant efficacy of IVIg in the treatment of the partially persisting facial nerve palsy and sensory ataxia, suggesting the potentially considerable use of IVIg as a therapeutic option in the treatment of similar neurological symptoms.

\section{Abbreviations \\ CSF: Cerebrospinal fluid; DRG: Dorsal root ganglia; EIA: Enzyme immunoassay; GBS: Guillain-Barré syndrome; ICI: Immune checkpoint inhibitor; Ig: Immunoglobulin; IVIg: Intravenous immunoglobulin; MRI: Magnetic resonance imaging; NCS: Nerve conduction studies; NSCLC: Non-small cell lung cancer; PD-1: Programmed cell death-1; PD-L1: Programmed cell death- ligand 1; PEM: Pemetrexed; PNS: Paraneoplastic neurological syndrome; RHS: Ramsay-Hunt syndrome; SCV: Sensory nerve conduction velocity; SEP: Somatosensory evoked potentials; SNAP: Sensory nerve action potential; VZV: Varicella-Zoster virus}

\section{Acknowledgements}

The authors thank Dr. Kenichi Kaida for performing the anti-ganglioside antibody tests (Department of Neurology and Anti-aging Medicine, National Defense Medical College, Saitama, Japan).

\section{Authors' contributions}

TS, MK, AM, and KS conceived of and designed this study. TS, MK, AM, SM, KS, SM and TK contributed to the analysis and interpretation of data. TS, MK, AM, and KS wrote the manuscript. YU supervised this study. KK critically reviewed the manuscript for important intellectual content. All authors have read and approved the final manuscript.

\section{Funding}

No funding was used to acquire the information/data described in this case report.

\section{Availability of data and materials}

Data sharing is not applicable for this case report, as no datasets were generated during the current study, which was based on clinical observations.

\section{Ethics approval and consent to participate}

This case report was approved by the local ethics committee of Toranomon Hospital (branch) (approval number \# 1840-B, 2019/5/7).

\section{Consent for publication}

Written informed consent for publication of this case report and the associated images was obtained from the patient.

\section{Competing interests}

The authors declare that they have no competing interests.

\section{Author details}

${ }^{1}$ Department of Respiratory Medicine, Toranomon Hospital (Branch), 1-3-1 Kajigaya, Takatsu-ku, Kawasaki-shi, Kanagawa 213-8587, Japan. ${ }^{2}$ Department of Neurology, Toranomon Hospital (Branch), 1-3-1 Kajigaya, Takatsu-ku, Kawasaki-shi, Kanagawa 213-8587, Japan. ${ }^{3}$ Okinaka Memorial Institute for Medical Research, 2-2-2 Toranomon Minato-ku, Tokyo 105-8470, Japan.

Received: 9 May 2019 Accepted: 9 December 2019

Published online: 16 December 2019

\section{References}

1. Brahmer J, Reckamp KL, Baas P, Crino L, Eberhardt WE, Poddubskaya E, et al. Nivolumab versus Docetaxel in advanced squamous-cell non-small-cell lung cancer. N Engl J Med. 2015;373:123-35.

2. Borghaei H, Paz-Ares L, Horn L, Spigel DR, Steins M, Ready NE, et al. Nivolumab versus Docetaxel in advanced nonsquamous non-small-cell lung cancer. N Engl J Med. 2015;373:1627-39.

3. Hottinger AF. Neurologic complications of immune checkpoint inhibitors. Curr Opin Neurol. 2016;29:806-12.

4. Tanaka R, Maruyama H, Tomidokoro Y, Yanagiha K, Hirabayashi T, Ishii A, et al. Nivolumab-induced chronic inflammatory demyelinating polyradiculoneuropathy mimicking rapid-onset Guillain-Barre syndrome: a case report. Jpn J Clin Oncol. 2016;46:875-8.

5. Larkin J, Chmielowski B, Lao CD, Hodi FS, Sharfman W, Weber J, et al. Neurologic serious adverse events associated with nivolumab plus ipilimumab or nivolumab alone in advanced melanoma, including a case series of encephalitis. Oncologist. 2017;22:709-18.

6. Gill C, Rouse S, Jacobson RD. Neurological complications of therapeutic monoclonal antibodies: trends from oncology to rheumatology. Curr Neurol Neurosci Rep. 2017;17:75.

7. Spain L, Walls G, Julve M, O'Meara K, Schmid T, Kalaitzaki E, et al. Neurotoxicity from immune-checkpoint inhibition in the treatment of melanoma: a single centre experience and review of the literature. Ann Oncol. 2017;28:377-85.

8. Fellner A, Makranz C, Lotem M, Bokstein F, Taliansky A, Rosenberg S, et al. Neurologic complications of immune checkpoint inhibitors. J Neuro-Oncol. 2018;137:601-9.

9. Del Castillo M, Romero FA, Arguello E, Kyi C, Postow MA, Redelman-Sidi G. The spectrum of serious infections among patients receiving immune checkpoint blockade for the treatment of melanoma. Clin Infect Dis. 2016; 63:1490-3.

10. Link H, Tibbling G. Principles of albumin and IgG analyses in neurological disorders. II. Relation of the concentration of the proteins in serum and cerebrospinal fluid. Scand J Clin Lab Invest. 1977;37:391-6.

11. House JW, Brackmann DE. Facial nerve grading system. Otolaryngol Head Neck Surg. 1985;93:146-7.

12. Adour KK. Otological complications of herpes zoster. Ann Neurol. 1994: 35(Suppl):S62-4.

13. Mishell JH, Applebaum EL. Ramsay-hunt syndrome in a patient with HIV infection. Otolaryngol Head Neck Surg. 1990;102:177-9.

14. JR H. On herpetic inflammation of the geniculate ganglion: a new syndrome and its complications. J Nerv Ment Dis. 1907;34:73-96.

15. Weinberg A, Levin MJ. VZV T cell-mediated immunity. Curr Top Microbiol Immunol. 2010;342:341-57.

16. Hanson DL, Chu SY, Farizo KM, Ward JW. Distribution of CD4+ T lymphocytes at diagnosis of acquired immunodeficiency syndrome-defining and other human immunodeficiency virus-related illnesses. The adult and adolescent spectrum of HIV disease project group. Arch Intern Med. 1995; 155:1537-42.

17. Shin EC, Rehermann B. Taking the brake off $T$ cells in chronic viral infection. Nat Med. 2006;12:276-7. 
18. Buonsenso D, Focarelli B, Valentini P, Onesimo R. IVIG treatment for VZVrelated acute inflammatory polyneuropathy in a child. BMJ Case Rep. 2012; 2012:bcr2012006362.

19. Kim JH, Kwon DH, Bae EY, Han SB, Lee JW, Chung NG, et al. Use of intravenous immunoglobulin in a disseminated varicella infection in an immunocompromised child. Korean J Pediatr. 2014;57:370-3.

20. Sheikh SI, Amato AA. The dorsal root ganglion under attack: the acquired sensory ganglionopathies. Pract Neurol. 2010;10:326-34.

\section{Publisher's Note}

Springer Nature remains neutral with regard to jurisdictional claims in published maps and institutional affiliations.

Ready to submit your research? Choose BMC and benefit from:

- fast, convenient online submission

- thorough peer review by experienced researchers in your field

- rapid publication on acceptance

- support for research data, including large and complex data types

- gold Open Access which fosters wider collaboration and increased citations

- maximum visibility for your research: over $100 \mathrm{M}$ website views per year

At BMC, research is always in progress.

Learn more biomedcentral.com/submissions 